\title{
Use of protein array technology to investigate receptor tyrosine kinases activated in hepatocellular carcinoma
}

\author{
SHI LIU ${ }^{1}$, JIAN GONG $^{1}$, ASAHIRO MORISHITA ${ }^{1}$, TAKAKO NOMURA $^{1}$, HISAAKI MIYOSHI $^{1}$, JOJI TANI $^{1}$, \\ KIYOHITO KATO $^{1}$, HIROHITO YONEYAMA ${ }^{1}$, AKIHIRO DEGUCHI ${ }^{1}$, HIROHITO MORI ${ }^{1}$, SHIMA MIMURA ${ }^{1}$, \\ KEI NOMURA ${ }^{1}$, TAKASHI HIMOTO ${ }^{1}$, KAZUSHI DEGUCHI ${ }^{1}$, KEIICHI OKANO ${ }^{2}$, KUNIHIKO IZUISHI ${ }^{2}$, \\ YASUYUKI SUZUKI ${ }^{2}$, YOSHIO KUSHIDA ${ }^{3}$, REIJI HABA ${ }^{3}$, HISAKAZU IWAMA ${ }^{4}$ and TSUTOMU MASAKI ${ }^{1}$ \\ Departments of ${ }^{1}$ Gastroenterology and Neurology, ${ }^{2}$ Gastroenterological Surgery, ${ }^{3}$ Diagnostic Pathology, and \\ ${ }^{4}$ Information Technology Center, Kagawa University School of Medicine, Kagawa 761-0793, Japan
}

Received October 13, 2010; Accepted January 28, 2011

DOI: $10.3892 / \mathrm{etm} .2011 .215$

\begin{abstract}
Receptor tyrosine kinases (RTKs) play a role in various processes, including cell growth, differentiation, apoptosis and carcinogenesis. RTKs are activated in various types of cancers, including breast, stomach, colon, pancreas and liver cancer and hepatocellular carcinoma (HCC). In the present study, protein array technology was used to analyze the expression status of various RTKs activated in HCC. The expression of activated RTKs was examined in the HCC cell lines, Alex, HuH7, Li-7, Hep3B, HLE and HLF; in the human normal hepatocyte cell line, hNHeps; and in human HCC and adjacent non-cancerous tissues. Of the 42 different phospho-RTKs, 15 (ErbB2, ErbB3, ErbB4, FGFR2 $\alpha$, FGFR3, insulin R, Mer, PDGFR $\beta$, c-Ret, ROR2, Tie, TrkA, VEGFR3, EphA1 and EphA4) were activated in some of the cancer cell lines studied. Among these, only ErbB2 was activated in all the HCC cell lines examined. Also, in vitro experiments were performed in subcutaneous HCC-bearing athymic nude mice to determine the therapeutic effects of inhibiting ErbB2 activation using the ErbB2-targeting drug trastuzumab. The results revealed that trastuzumab markedly suppressed the growth of HCC. These data suggest that ErbB2 is activated in HCC and that trastuzumab may play a role in the treatment of this disease. In addition, the use of protein array technology is proposed as a tool for detecting the expression of activated RTKs and identifying an effective RTK-based therapy.
\end{abstract}

\section{Introduction}

Hepatocellular carcinoma (HCC) is one of the most serious malignancies worldwide (1), particularly in Asian countries

Correspondence to: Dr Tsutomu Masaki, Department of Gastroenterology and Neurology, Kagawa University School of Medicine, 1750-1 Ikenobe, Miki-cho, Kita-gun, Kagawa 761-0793, Japan

E-mail: tmasaki@med.kagawa-u.ac.jp

Key words: receptor tyrosine kinases, hepatocellular carcinoma due to the high prevalence of the hepatitis virus (2). It is also the third most common cause of cancer-related mortality $(3,4)$. Despite intensive efforts to develop novel treatment modalities for HCC, the prognosis remains poor. Thus, there is a strong demand for effective new approaches to HCC therapy.

Receptor tyrosine kinases (RTKs) are a family of 56 proteins each characterized by a transmembrane domain and a tyrosine kinase motif (5). The known RTKs consist of a ligand-binding domain at the extracellular surface, a single transmembrane segment and a cytoplasmic part harboring the protein kinase activity. They are divided into 21 families, including the epidermal, vascular endothelial and fibroblast growth factor receptor families, which are characterized by a similar structure and the potential for intrafamilial dimerization (6). Various RTKs have been implicated in intracellular signal transduction pathways involved in growth, differentiation, adhesion, migration, apoptosis and carcinogenesis (7). In regard to the relationship between human cancers and RTKs, aberrant RTK activity was initially found in various epithelial cancers, including breast (8), gastric (9), lung (10), colon (11) and esophageal cancer $(12)$, and $\operatorname{HCC}(13,14)$. It is now accepted that the activation of certain RTKs plays a key role in the development of almost all types of cancer. Accordingly, a number of clinical trials with various settings and designs are currently exploring the potential of anti-RTK therapies in various cancers (15). A recent study reported that the receptor tyrosine kinase inhibitor sorafenib is effective in patients with advanced HCC (16). However, the anti-cancer effects of sorafenib under investigation for the treatment of $\mathrm{HCC}$ remain unknown.

The aims of this study were two-fold: i) to use protein array technology to determine the expression status of various activated RTKs in HCC; and ii) upon identifying ErbB2 as the most consistently up-regulated RTK, to investigate whether an ErbB2-targeting drug, trastuzumab, would be effective as an anti-cancer agent in an HCC xenograft model.

\section{Materials and methods}

Materials. The RayBio ${ }^{\mathrm{TM}}$ Human Phospho Array kit (catalog no. ARY 001) was purchased from RayBiotech Inc. (Norcross, 


\begin{tabular}{|c|c|c|c|c|c|c|c|c|c|c|c|}
\hline $\begin{array}{l}\text { PY- } \\
\text { Control }\end{array}$ & & & & & & & & & & & $\begin{array}{l}\text { PY- } \\
\text { Control }\end{array}$ \\
\hline EGFR & ErbB2 & ErbB3 & ErbB4 & FGFR1 & FGFR2 $\alpha$ & FGFR3 & FGFR4 & Insulin R & IGF-1R & Axl & Dtk \\
\hline Mer & HGFR & MSPR & PDGFR $\alpha$ & PDGFR $\beta$ & SCFR & Flt-3 & M-CSFR & c-Ret & ROR1 & ROR2 & Tie-1 \\
\hline Tie-2 & TrkA & TrkB & TrkC & VEGFR1 & VEGFR2 & VEGFR3 & MuSK & EphA1 & EphA2 & EphA3 & EphA4 \\
\hline EphA6 & EphA7 & EphB1 & EphB2 & EphB4 & EphB6 & $\begin{array}{l}\text { Mouse } \\
\text { IgG1 }\end{array}$ & $\begin{array}{l}\text { Mouse } \\
\text { IgG2A }\end{array}$ & $\begin{array}{l}\text { Mouse } \\
\text { IgG2B }\end{array}$ & Goat IgG & PBS & \\
\hline $\begin{array}{l}\text { PY- } \\
\text { Control }\end{array}$ & & & & & & & & & & & $\begin{array}{l}\text { PY- } \\
\text { Control }\end{array}$ \\
\hline
\end{tabular}

Figure 1. Template showing the location of a tyrosine kinase antibody spotted onto a RayBio ${ }^{\mathrm{TM}}$ Human phospho array. PY-Control, phospho-tyrosine positive control; EGFR, epidermal growth factor receptor; ErbB2, v-erb-b2 erythroblastic leukemia viral oncogene homolog 2; ErbB3, v-erb-b2 erythroblastic leukemia viral oncogene homolog 3; ErbB4, v-erb-a erythroblastic leukemia viral oncogene homolog 4; FGFR, fibroblast growth factor receptor; Insulin R, insulin receptor; IGF-1R, insulin-like growth factor I receptor; Axl, Axl receptor tyrosine kinase; Dtk, developmental receptor tyrosine kinase; Mer, tyrosineprotein kinase Mer; HGFR, hepatocyte growth factor receptor; MSPR, macrophage stimulatory protein receptor; PDGFR, platelet-derived growth factor receptor; SCFR, stem-cell factor receptor; Flt-3, Fms-like tyrosine kinase 3; M-CSFR, macrophage colony-stimulating factor receptor; c-Ret, receptor tyrosine kinase c-ret; ROR, receptor tyrosine kinase-like orphan receptor; Tie, tyrosine kinase with immunoglobulin-like and EGF-like domains; TrkA, neurotrophic tyrosine kinase, receptor, type 1; TrkB, neurotrophic tyrosine kinase, receptor, type 2; TrkC, neurotrophic tyrosine kinase, receptor, type 3; VEGFR, vascular endothelial growth factor receptor; MuSK, muscle, skeletal, receptor tyrosine kinase; Eph, Eph receptor; PBS, phosphate-buffered saline.

GA, USA). Trastuzumab (Herceptin $\left.{ }^{\mathrm{TM}}\right)$ was purchased from Chugai Pharmaceutical Co., Ltd. (Tokyo, Japan).

Human tissues. Human HCC tissue samples and the adjacent hepatic tissues were obtained during surgery from 5 patients (3 male and 2 female; mean age 69.6 \pm 10.6 years; range $57-81$ ). A total of 3 patients were positive for hepatitis C virus RNA, and 2 patients with chronic hepatitis were positive for the hepatitis B surface antigen. The histology of the adjacent hepatic tissue in the patients was F4 according to Desmet's classification (17). None of the patients had received any chemotherapy or radiotherapy prior to surgery. The use of human specimens was approved by the Human Subjects Committee of Kagawa University School of Medicine.

Cell lines. Alex, HuH7, Li-7, Hep3B, HLE and HLF cells, a kind gift from the Japanese Cancer Resource Bank (Tokyo, Japan), were used as the HCC cell lines. These cell lines were plated at a density of $1 \times 10^{5}$ cells $/ \mathrm{cm}^{3}$ in plastic flasks containing Dulbecco's modified minimum essential medium (DMEM) (Gibco BRL Co., Grand Island, NY, USA) supplemented with $10 \%$ heat-inactivated fetal calf serum, $100 \mu \mathrm{g} / \mathrm{ml}$ penicillin and $100 \mu \mathrm{g} / \mathrm{ml}$ streptomycin at $37^{\circ} \mathrm{C}$ in $5 \% \mathrm{CO}_{2}$ in air. The human normal hepatocyte cell line, hNHeps, was used as the normal hepatocyte cell line.

Cell and tissue lysates. The cell lysate was prepared according to the methods previously described $(9,18,19)$. The steps were performed at $4^{\circ} \mathrm{C}$. The protein concentration of the cell and tissue lysates was measured using a dye-binding protein assay based on the Bradford method $(13,14,20)$.

Antibody arrays of phospho-receptor tyrosine kinases. An assay for phospho-RTK array was performed as previously described $(9,11)$. Briefly, phospho-RTK array membranes were blocked with 5\% BSA/TBS (0.01 M Tris HCl, pH 7.6) for $1 \mathrm{~h}$. The membranes were subsequently incubated with $\sim 2 \mathrm{ml}$ (protein contents: $100 \mu \mathrm{g} / \mathrm{ml}$ ) of lysate prepared from cell lines or tissues after normalization with equal amounts of protein. To remove unbound materials, the membranes were washed three times with TBS, including $0.1 \% \mathrm{v} / \mathrm{v}$ Tween- 20 for $10 \mathrm{~min}$ each time, and then twice with TBS alone for $10 \mathrm{~min}$ each time. They were then incubated with anti-phosphotyrosine-HRP antibody for $2 \mathrm{~h}$ at room temperature. The unbound HRP antibody was washed out with TBS, including $0.1 \%$ Tween-20. Finally, each array membrane was exposed to X-ray film using a chemiluminescence detection system (Amersham Life Sciences, Tokyo, Japan).

In vivo anti-tumor effects of trastuzumab on hepatocellular carcinoma. Athymic 8-week-old male BALB/c-nu/ nu mice, weighing 20-22 g, were purchased from Japan SLC (Hamamatsu, Shizuoka, Japan) and kept under specific pathogen-free conditions at $24 \pm 2^{\circ} \mathrm{C}$. The animal experiments were performed with approved protocols and in accordance with the institutional recommendations for the proper care and use of laboratory animals. HuH7 and HLF HCC cells were suspended in PBS at a concentration of $5 \times 10^{7}$ cells/ $\mathrm{ml}$, respectively, and $100 \mu \mathrm{l}$ inoculum volumes were injected subcutaneously into the flank regions of the mice. When the tumors became palpable in the treated group $(\mathrm{n}=10), 500 \mu \mathrm{l}$ of PBS containing $750 \mathrm{mg} / 0.5 \mathrm{ml}$ trastuzumab (Herceptin ${ }^{\circledR}$, directed against the ErbB2 receptor, also known as the Her2/ Neu oncogene) was administered intraperitoneally three times a week for 3 weeks. Only PBS was administered to the control group $(\mathrm{n}=10)$. After initiation of the trastuzumab administration, the tumor growth was monitored by the same investigators (I.G. and T.M.), and the tumor diameters were measured every week using a graduated caliper. Tumor growth was assessed weekly by measuring the two greatest perpendicular tumor dimensions. Tumor volume was calculated as follows: tumor volume $\left(\mathrm{mm}^{3}\right)=$ [tumor length $(\mathrm{mm})$ $\mathrm{x}$ tumor width $\left.(\mathrm{mm})^{2}\right] / 2(21)$. The animals were sacrificed on day 16 after treatment. The animals remained alive throughout the observation.

Statistical analysis. The results are expressed as the means $\pm \mathrm{SD}$. The analysis was performed using the computer-assisted StatView program (SAS Institute, Cary, NC, USA). Paired analysis between two groups was performed using the 


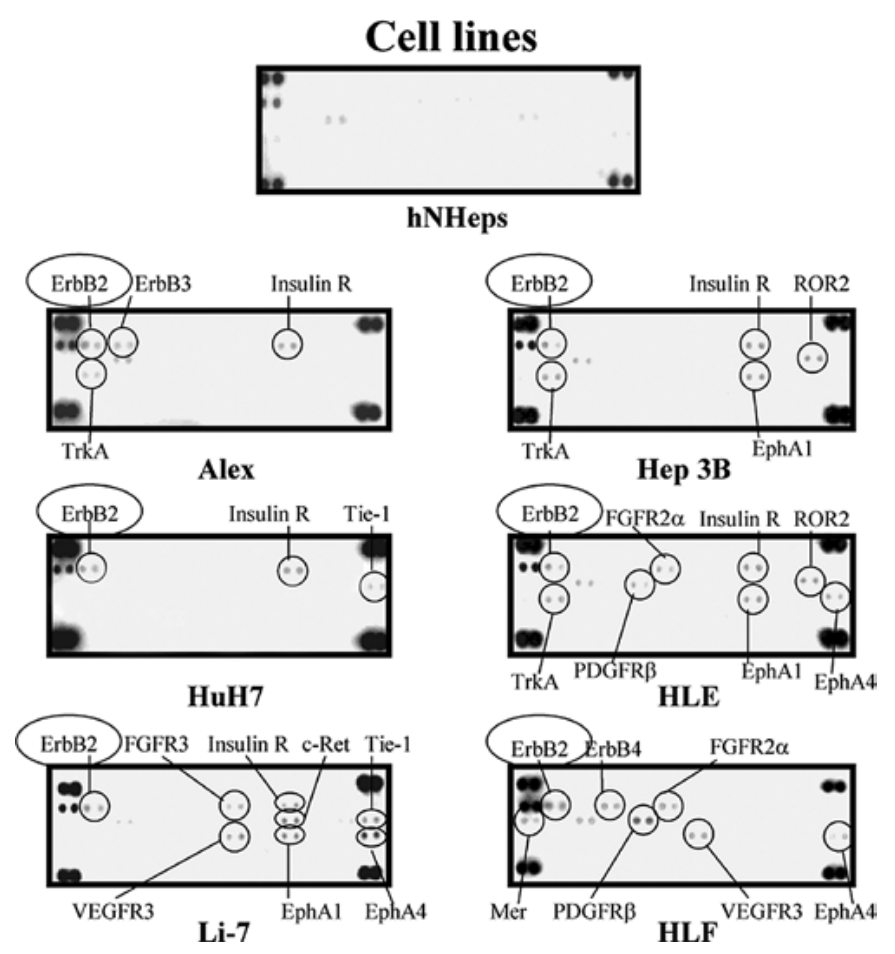

Figure 2. Representative expression in the hNHeps and HCC cell lines of various tyrosine kinases, including Alex, HuH7, Li-7, Hep3B, HLE and HLF. As compared to the hNHeps cell line, ErbB2, ErbB3, ErbB4, insulin R, ROR2, TrkA, EphA1, Tie-1, FGFR2 $\alpha$, FGFR3, PDGFR $\beta$, EphA4, c-Ret, Mer and VEGFR3 were up-regulated in some of the cancer cell lines studied. The up-regulation of ErbB2 (•) was detected in all of the HCC cell lines examined in this study, while it was not detected in the hNHeps cell line.

Student's t-test. Values of $\mathrm{p}<0.05$ were considered to indicate a significant difference between groups.

\section{Results}

Activity level of activated receptor tyrosine kinases is associated with hepatocellular carcinoma. A phospho-RTK array system was used to identify the 'key RTKs' that are associated with HCC. Using the antibody array, the expression of 42 different activated RTKs were simultaneously screened (Fig. 1). Compared to the hNHeps cell line, ErbB2, ErbB3, ErbB4, FGFR2 $\alpha$, FGFR3, insulin R, Mer, PDGFR $\beta$, c-Ret, ROR2, Tie, TrkA, VEGFR3, EphA1 and EphA4 were upregulated in some of cancer cell lines studied (Fig. 2). One of these molecules, ErbB2 (•), was up-regulated in all of the HCC cell lines examined in this study, while it was not detected in the hNHeps cell line. Also, in the cancerous tissue, ErbB2 was the only RTK up-regulated in all five tissue samples (Fig. 3). These results suggest that an ErbB2-targeting drug is a useful agent for the treatment of HCC.

In vivo anti-tumor effects of an ErbB2-targeting drug, trastuzumab. Athymic 8-week-old male BALB/c-nu/nu mice were implanted subcutaneously with HuH7 and HLF cells. When the animals developed palpable tumors, they were treated intraperitoneally with trastuzumab three times a week for 3 weeks. Animals in the control group received intraperitoneal administration of the vehicle (PBS).
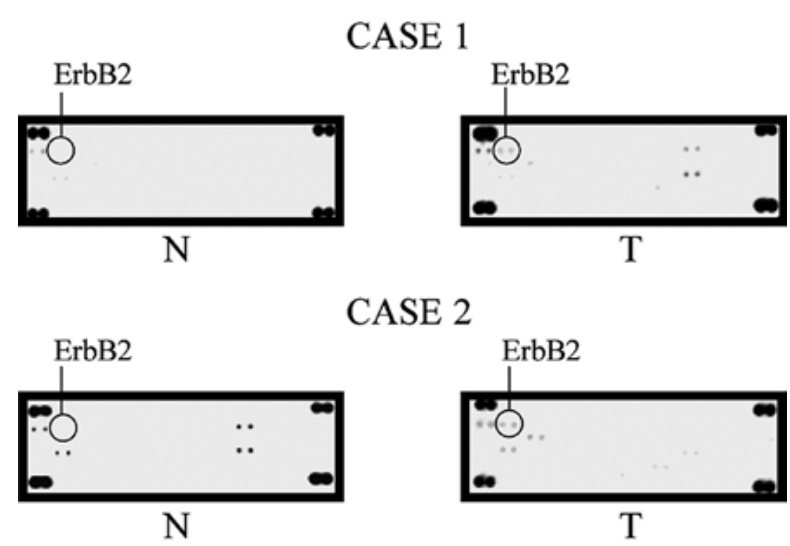

CASE 2

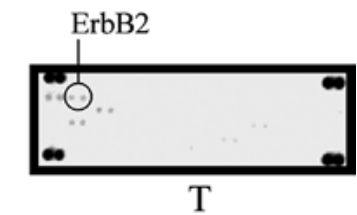

Figure 3. Representative sample results $(n=2)$ revealing marked increase of $\mathrm{ERbB}_{2}$ activation in cancerous tissue $(\mathrm{T})$ when compared to pair-matched non-tumorous tissues $(\mathrm{N})$.

As shown in Fig. 4A, animals in the control group that were implanted subcutaneously with $\mathrm{HuH7}$ cells developed rapidly growing subcutaneous HCC while animals in the trastuzumab group exhibited significantly retarded tumor development compared to the animals in the control group (Fig. 4A). Fig. 4B shows representative images of gross $\mathrm{HuH} 7$ tumors from nude mice treated with either trastuzumab or vehicle.

As shown in Fig. 4C, the tumor size increased until the sixth day after implantation in the control animals implanted subcutaneously with HLF cells, but decreased gradually thereafter. By contrast, the animals in the trastuzumab group exhibited significantly retarded tumor development, and the tumors in 4/5 animals disappeared. Fig. 4D shows representative images of gross HLF tumors from the nude mice treated with either trastuzumab or the vehicle. The tumors in the trastuzumab group disappeared completely while the tumors in the control group did not disappear.

Animals in the trastuzumab group implanted with the strains HuH7 or HLE did not show substantial changes, while those in the control group showed disheveled fur and decreased body weight. The animals remained alive throughout the experiment.

\section{Discussion}

The human epidermal growth factor receptor 2 (HER2) gene, also known as ErbB2, encodes a $185-\mathrm{kDa}$ transmembrane glycoprotein receptor. This receptor belongs to the ErbB family of growth factor receptors with intrinsic tyrosine kinase activity, the membranes of which exist in homodimer and heterodimer forms when activated (22).

ErbB2 is activated by ligand-binding in its extracellular region and subsequently the intracellular tyrosine kinase region is phosphorylated and sends signals to the cell to regulate numerous crucial processes (23), including growth, differentiation and carcinogenesis.

Overexpression of ErbB2 is frequently observed in a variety of tumor types (24-29), including colon, gastric, nonsmall cell lung, epithelial ovarian (30), endometrial carcinoma $(31,32)$, prostate $(33)$, urinary bladder (34) and uterine papillary serous cancers $(35,36)$. Although overexpression of ErbB2 is rarely observed in HCC, mutation of ErbB2 is found in $11 \%$ 
A

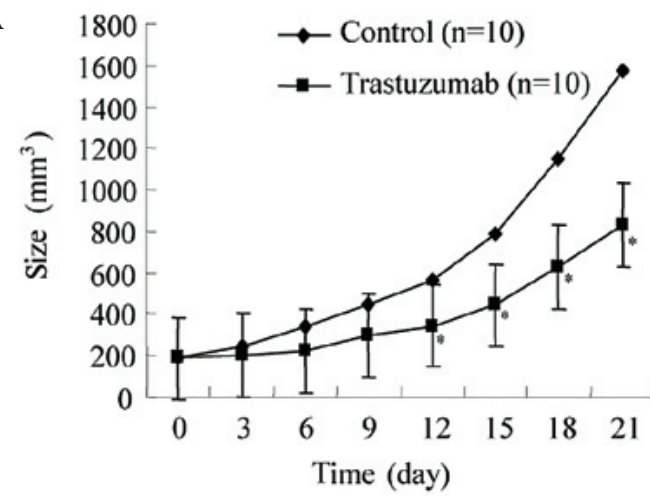

B

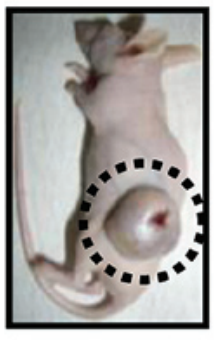

Control

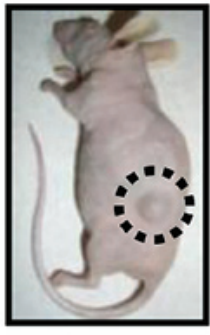

Trastuzumab

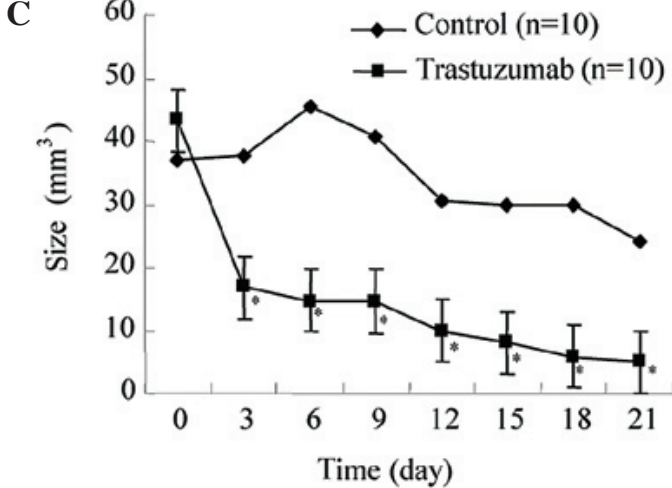

D

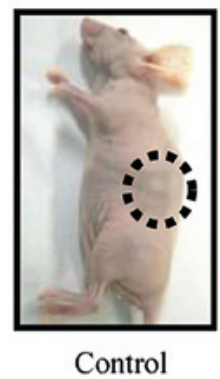

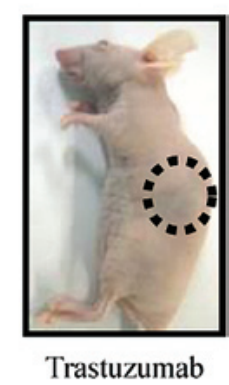

Figure 4. In vivo anti-tumor effects of trastuzumab on established HCC with HuH7 and HLF cells in nude mice. (A) HuH7 cells were implanted subcutaneously into the flank regions of nude mice. When tumors became palpable, $750 \mu \mathrm{g}$ trastuzumab was injected intraperitoneally three times a week for 3 weeks. Animals in the control group developed rapidly growing subcutaneous HCC. Animals in the trastuzumab groups exhibited significantly retarded tumor development compared to the animals in the control group. Each data point represents the mean \pm SD of 10 animals. * $<0.001$. (B) Representative images of gross $\mathrm{HuH7}$ cell tumors from the nude mice treated with either control or trastuzumab, respectively. (C) In vivo tumor anti-tumor effects of trastuzumab on established HCC with HLF cells in nude mice. HLF cells were implanted subcutaneously into the flank regions of nude mice. When tumors became palpable, $750 \mu \mathrm{g}$ trastuzumab was injected intraperitoneally three times a week for 3 weeks. The tumors decreased gradually from the sixth day both in the control and the trastuzumab groups. However, animals in the trastuzumab groups exhibited significantly retarded tumor development compared to animals in the control group. Each data point represents the mean \pm SD of 10 animals. * $<<0.001$. (D) Representative images of gross HLF cell tumors from nude mice treated with either control or trastuzumab, respectively. The tumors in the control group did not disappear, while the tumors in the trastuzumab group disappeared completely.

of cases (37). Therefore, ErbB2 is targeted using antibodies directed against the extracellular domain in various types of human cancers, including HCC. These strategies have been successful in the area of breast cancer (25). However, there is currently no evidence supporting a potential role for trastuzumab in HCC comparable to its role in breast cancer. Thus, in the present study we examined the possibility of an antitumor effect of trastuzumab in HCC.

In the present study, we first identified the 'key RTKs' associated with HCC by studying 42 activated phospho-RTKs, using the phospho-RTK array system (Fig. 1). As a result, ErbB2 was found to be activated in all six of the HCC cell lines examined (Fig. 2), and in all cancerous samples (Fig. 3). Next, we determined that the inhibition of ErbB2 by trastuzumab retarded the tumor development of HCC cells ( $\mathrm{HuH7}$ and HLF). These data suggest that an ErbB2-targeting drug will aid in the treatment of HCC.

Our studies demonstrated that ErbB2, ErbB3, ErbB4, insulin R, ROR2, TrkA, EphA1, Tie-1, FGFR2 $\alpha$, FGFR3, PDGFR $\beta$, EphA4, c-Ret, VEGFR3 and Mer were up-regulated in some of the cancer cell lines studied. Overexpression of ErbB2, ErbB3, TrkA, EphA1, Tie-1, FGFR2, FGFR3, PDGFR, Ret and VEGFR3 was previously reported in HCC (38-46). These previous reports support our results on the various RTKs activated in HCC derived from the protein array in this study. In summary, our results suggest that protein arrays aid in studying the expression of activated RTKs in various tissues, including malignant tissues. Furthermore, these results suggest that the immunological inhibition of ErbB3, ErbB4, insulin R, ROR2, TrkA, EphA1, Tie-1, FGFR2 $\alpha$, FGFR3, PDGFR $\beta$, EphA4, c-Ret, VEGFR3 and Mer in addition to ErbB2 also have an anti-tumor effect for certain cases of HCC.

In conclusion, the ErbB2-targeting drug trastuzumab may aid in the treatment of HCC. In addition, the present results suggest that protein arrays are useful for detecting the expression of activated RTKs and developing efficient RTK-targeted therapies for HCC.

\section{References}

1. Parkin DM, Bray F, Ferlay J and Pisani P: Global cancer statistics, 2002. CA Cancer J Clin 55: 74-108, 2005.

2. Poon D, Anderson BO, Chen LT, et al: Management of hepatocellular carcinoma in Asia: consensus statement from the Asian Oncology Summit 2009. Lancet Oncol 10: 1111-1118, 2009.

3. Robinson DR, Wu YM and Lin SF: The protein tyrosine kinase family of the human genome. Oncogene 19: 5548-5557, 2000.

4. Parkin DM: Global cancer statistics in the year 2000. Lancet Oncol 2: 533-543, 2001.

5. Becker JC, Muller-Tidow C, Serve H, Domschke W and Pohle T: Role of receptor tyrosine kinases in gastric cancer: new targets for a selective therapy. World J Gastroenterol 12: 3297-3305, 2006. 
6. Hubbard SR and Till JH: Protein tyrosine kinase structure and function. Annu Rev Biochem 69: 373-398, 2000.

7. Tanner M, Hollmen M, Junttila TT, et al: Amplification of HER-2 in gastric carcinoma: association with Topoisomerase IIalpha gene amplification, intestinal type, poor prognosis and sensitivity to trastuzumab. Ann Oncol 16: 273-278, 2005.

8. Svensson S, Jirström K, Rydén L, Roos G, Emdin S, Ostrowski MC and Landberg G: ERK phosphorylation is linked to VEGFR2 expression and Ets-2 phosphorylation in breast cancer and is associated with tamoxifen treatment resistance and small tumours with good prognosis. Oncogene 24: 4370-4379, 2005.

9. Gong J, Morishita A, Kurokohchi K, et al: Use of protein array to investigate receptor tyrosine kinases activated in gastric cancer. Int J Oncol 36: 101-106, 2010.

10. Cao C, Albert JM, Geng L, Ivy PS, Sandler A, Johnson DH and $\mathrm{Lu} \mathrm{B}$ : Vascular endothelial growth factor tyrosine kinase inhibitor AZD2171 and fractionated radiotherapy in mouse models of lung cancer. Cancer Res 66: 11409-11415, 2006.

11. Morishita A, Gong J, Nomura T, et al: The use of protein array to identify targetable receptor tyrosine kinases for treatment of human colon cancer. Int J Oncol 37: 829-835, 2010.

12. Zhang G, Zhang Q, Zhang Q, et al: Expression of nucleostemin, epidermal growth factor and epidermal growth factor receptor in human esophageal squamous cell carcinoma tissues. J Cancer Res Clin Oncol 136: 587-594, 2010.

13. Masaki T, Tokuda M, Yoshida S, et al: Comparison study of the expression of myristoylated alanine-rich $\mathrm{C}$ kinase substrate in hepatocellular carcinoma, liver cirrhosis, chronic hepatitis, and normal liver. Int J Oncol 26: 661-671, 2005.

14. Yoshida S, Masaki T, Feng H, et al: Enhanced expression of adaptor molecule p46 Shc in nuclei of hepatocellular carcinoma cells: study of LEC rats. Int J Oncol 25: 1089-1096, 2004.

15. Bennasroune A, Gardin A, Aunis D, Crémel G and Hubert P. Tyrosine kinase receptors as attractive targets of cancer therapy. Crit Rev Oncol Hematol 50: 23-38, 2004.

16. Llovet JM, Ricci S, Mazzaferro V, et al: Sorafenib in advanced hepatocellular carcinoma. N Engl J Med 359: 378-390, 2008.

17. Desmet VJ, Gerber M, Hoofnagle JH, Manns M and Scheuer PJ: Classification of chronic hepatitis: diagnosis, grading and staging. Hepatology 19: 1513-1520, 1994.

18. Yukimasa S, Masaki T, Yoshida S, et al: Enhanced expression of p46 Shc in the nucleus and p52 Shc in the cytoplasm of human gastric cancer. Int J Oncol 26: 905-911, 2005

19. Mohammad HS, Kurokohchi K, Yoneyama H, et al: Annexin A2 expression and phosphorylation are up-regulated in hepatocellular carcinoma. Int J Oncol 33: 1157-1163, 2008.

20. Nonomura T, Masaki T, Morishita A, et al: Identification of c-Yes expression in the nuclei of hepatocellular carcinoma cells: involvement in the early stages of hepatocarcinogenesis. Int J Oncol 30: 105-111, 2007.

21. D'Incalci M, Colombo T, Ubezio P, et al: The combination of yondelis and cisplatin is synergistic against human tumor xenografts. Eur J Cancer 39: 1920-1926, 2003.

22. Bazley LA and Gullick WJ: The epidermal growth factor receptor family. Endocr Relat Cancer 12: 17-27, 2005.

23. Schlessinger J: Ligand-induced, receptor-mediated dimerization and activation of EGF receptor. Cell 110: 669-672, 2002.

24. Hermanova M, Lukas Z, Nenutil R, et al: Amplification and overexpression of HER-2/neu in invasive ductal carcinomas of the pancreas and pancreatic intraepithelial neoplasms and the relationship to the expression of p21 (WAF1/CIP1). Neoplasma 51: 77-83, 2004.

25. Friess T, Scheuer W and Hasmann M: Erlotinib antitumor activity in non-small cell lung cancer models is independent of HER 1 and HER2 overexpression. Anticancer Res 26: 3505-3512, 2006.

26. Hatake K, Tokudome $\mathrm{N}$ and Ito Y: Tanstuzumab treatment for breast cancer. Intern Med 46: 149-150, 2007.

27. Larbouret C, Robert B, Navarro-Teulon I, et al: In vivo therapeutic synergism of anti-epidermal growth factor receptor and anti-HER2 monoclonal antibodies against pancreatic carcinomas. Clin Cancer Res 13: 3356-3362, 2007.
28. Lara PN Jr, Chee KG, Longmate J, et al: Trastuzumab plus docetaxel in HER-2/neu-positive prostate carcinoma: final results from the California Cancer Consortium Screening and Phase II Trial. Cancer 100: 2125-2131, 2004.

29. Shun CT, Wu MS, Lin JT, et al: Relationship of p53 and c-erbB-2 expression to histopathological features, Helicobacter pylori infection and prognosis in gastric cancer. Hepatogastroenterology 44: 604-609, 1997.

30. Berchuck A, Kamel A, Whitaker R, et al: Overexpression of her $2 /$ neu is associated with poor survival in advanced epithelial ovarian cancer. Cancer Res 50: 4087-4091, 1990.

31. Grushko TA, Filiaci VL, Mundt AJ, Ridderstråle K, Olopade OI, Fleming GF and Gynecologic Oncology Group: An exploratory analysis of HER-2 amplification and overexpression in advanced endometrial carcinoma: a Gynecologic Oncology Group study. Gynecol Oncol 108: 3-9, 2008.

32. Saffari B, Jones LA, el-Naggar A, Felix JC, George J and Press MF: Amplification and overexpression of HER-2/neu (c-erbB2) in endometrial cancers: correlation with overall survival. Cancer Res 55: 5693-5698, 1995.

33. Ross JS, Sheehan C, Hayner-Buchan AM, et al: HER-2/neu gene amplification status in prostate cancer by fluorescence in situ hybridization. Hum Pathol 28: 827-833, 1997.

34. Sato K, Moriyama M, Mori S, et al: An immunohistologic evaluation of C-erbB-2 gene product in patients with urinary bladder carcinoma. Cancer 70: 2493-2498, 1992.

35. Slomovitz BM, Broaddus RR, Burke TW, et al: Her-2/neu overexpression and amplification in uterine papillary serous carcinoma. J Clin Oncol 22: 3126-3132, 2004.

36. Villella JA, Cohen S, Smith DH, Hibshoosh H and Hershman D: HER-2/neu overexpression in uterine papillary serous cancers and its possible therapeutic implications. Int J Gynecol Cancer 16: $1897-1902,2006$

37. Bekaii-Saab T, Williams N, Plass C, Calero MV and Eng C: A novel mutation in the tyrosine kinase domain of ERBB2 in hepatocellular carcinoma. BMC Cancer 6: 278, 2006.

38. Fuchs BC, Fujii T, Dorfman JD, et al: Epithelial-to-mesenchymal transition and integrin-linked kinase mediate sensitivity to epidermal growth factor receptor inhibition in human hepatoma cells. Cancer Res 68: 2391-2399, 2008.

39. Neo SY, Leow CK, Vega VB, et al: Identification of discriminators of hepatoma by gene expression profiling using a minimal dataset approach. Hepatology 39: 944-953, 2004.

40. Rasi G, Serafino A, Bellis L, et al: Nerve growth factor involvement in liver cirrhosis and hepatocellular carcinoma. World $\mathrm{J}$ Gastroenterol 13: 4986-4995, 2007.

41. Chen G, Wang Y, Zhou M, Shi H, Yu Z, Zhu Y and Yu F: EphA1 receptor silencing by small interfering RNA has antiangiogenic and antitumor efficacy in hepatocellular carcinoma. Oncol Rep 23: 563-570, 2010

42. Dhar DK, Naora H, Yamanoi A, Ono T, Kohno H, Otani H and Nagasue N: Requisite role of VEGF receptors in angiogenesis of hepatocellular carcinoma: a comparison with angiopoietin/Tie pathway. Anticancer Res 22: 379-386, 2002.

43. Harimoto N, Taguchi K, Shirabe K, et al: The significance of fibroblast growth factor receptor 2 expression in differentiation of hepatocellular carcinoma. Oncology 78: 361-368, 2010.

44. Qiu WH, Zhou BS, Chu PG, et al: Over-expression of fibroblast growth factor receptor 3 in human hepatocellular carcinoma. World J Gastroenterol 11: 5266-5272, 2005

45. Avila MA, Berasain C, Sangro B and Prieto J: New therapies for hepatocellular carcinoma. Oncogene 25: 3866-3884, 2006.

46. Musholt PB, Imkamp F, von Wasielewski R, Schmid KW and Musholt TJ: RET rearrangements in archival oxyphilic thyroid tumors: new insights in tumorigenesis and classification of Hürthle cell carcinomas? Surgery 134: 881-889, 2003. 